\title{
Overweight/Obesity-Related Attitudes and Self-Care Behaviours: Evaluation and Comparison of the Protection Motivation Model and Theory of Planned Behaviour
}

\author{
Robert Tack Kwei Ho and Xiao Yuan Sun \\ Assumption University of Thailand, Bangkok, Thailand
}

\begin{abstract}
$T^{\text {then }}$ he present study identified, evaluated, and compared two health belief/attitudinal models (protection motivation theory and the theory of planned behaviour) that explain the decision-making processes associated with both the intention for and engagement in self-care overweight/obesity-reducing behaviours. Multi-model analysis with a sample of 1,100 participants indicated that the theory of planned behaviour offered a better representation of, and provided a more potent theoretical framework than the protection motivation model in explaining the decision-making processes underlying both the intention for and engagement in self-care overweight/obesity-reducing behaviours. Employment of multi-group analysis yielded no significant gender differences in the adoption of overweight/obesity-reducing behaviours, which suggest similar decision-making processes for males and females. The implications of these findings with regard to the role that health beliefs and attitudes play as key predictors of the decision of whether or not to engage in self-care overweight/obesity-related behaviours are discussed.
\end{abstract}

Keywords: obesity, overweight, protection motivation, theory of planned behaviour

Overweight and obesity, usually examined in concert, have progressively become serious health problems worldwide with over 1.5 billion adults (older than 20 years) classified as overweight and over 200 million men and nearly 300 million women classified as obese in 2008 (World Health Organization [WHO], 2011). Although their frequencies are relatively lower in Asia, perhaps because of healthier traditional diets such as those seen in Korea and Japan, the rise in the number of Asian people classified as overweight and/or obese has also reached alarming levels, with nearly 18 million Asian children being affected by overweight and obesity (Onis et al., 2010). The statistics are equally worrisome in Thailand, where traditional diets have been replaced by more fashionable Western fast foods high in protein, fats, and cholesterol. According to the WHO Global Infobase (WHO, 2010), the conditions of overweight and obesity increased significantly among the Thai population between the years 2002 and 2010 and will most likely increase in the next decade. More specifically, statistics presented by the WHO Global Infobase (WHO, 2010) showed that for Thai people older than 15 years, the prevalence of overweight was $22.7 \%$ among males and $32.5 \%$ among females in 2002 , rising to $28.3 \%$ and $39.9 \%$ respectively for males and females in 2010 . The prevalence of obesity was also found to have increased significantly across the same time period, from $2.5 \%$ for males and $7 \%$ for females to $2.6 \%$ and $11.1 \%$ respectively for males and females.

Regardless of cultural and/or demographic differences, many researchers have indicated that being overweight and obese are the leading causes of many negative health consequences, both physical and psychological. For physical health, overweight and obesity are major risk factors for premature mortality, cardiovascular disease, Type 2 diabetes, arthritis, hypertension, and cancer (Manson \& Bassuk, 2003). According to the WHO (2012), patients with obesity-related disease are often categorised under disability-adjusted life year (DALY), a measure of overall disease burden and death-risk. Psychologically, overweight and obesity also bring greater risks for developing body image dissatisfaction (Vander Wal \& Thelen, 2000), higher rates of anxiety disorders (Vila et al., 2004), lower

Address for correspondence: Robert Tack Kwei Ho, Graduate Schools of Education and Psychology, Assumption University of Thailand, Hua Mak Campus, 592 Ram Khamhaeng Rd., Soi 24, Hua Mak, Bangkok 10240, Thailand. Email: tack.kwei@gmail.com 
self-esteem (Pesa, Syre, \& Jones, 2000), and mood disorder (Simon et al., 2006).

When considering the antecedents of being overweight and/or obese, there is clearly a paradox in the observation that while most people are aware that a healthy diet and regular exercise help to control weight, the incidence and frequency of overweight and obesity have remained alarmingly high and seemingly irreversible. While there has been increased interest in the epidemiology, biological mechanisms, and consequences of these conditions among health researchers, the psychological reasons why people become overweight and obese remain unclear. While descriptive statistics and conceptualisations of overweight and obesity may help to enhance our understanding of the extent of these health risk problems, there is clearly a need to further explore and understand the psychological factors that motivate people to engage in behaviours that may lead to the high probability of being overweight and/or obese, even in the face of overwhelming evidence of negative health consequences. That is, the clear demonstration of contingency between poor lifestyle behaviours (e.g., consumption of a high-fat diet, lack of regular exercise, sedentary lifestyle) and overweight and obesity emphasises the need for understanding the decision-making processes underlying people's attitudes about health and their adoption of self-care health behaviours. The present study has been designed to investigate the decision-making processes involved in the intention for, as well as engagement in, obesity-related self-care behaviours. A clear understanding of these decision-making processes may lead to the development of intervention strategies that may help people control excessive weight gain.

\section{Health Belief Models}

Numerous health belief models have been proposed to explain the adoption of health-protective behaviours, and in particular the cognitive appraisal processes that underlie the decision to adopt or not adopt protective health behaviour, as well as to predict patterns of change. This cognitive perspective includes theories such as the health belief model (HBM; Becker, 1974), social-cognitive theory (SCT; Bandura, 1986), the theory of planned behaviour (TPB; Ajzen \& Madden, 1986), protection motivation theory (PMT; Rogers, 1983, 1984), and the transtheoretical model (TTM; Prochaska \& DiClemente, 1983). While these theories differ in terms of the cognitive variables that are hypothesised to influence behaviour change, they all share the assumption that attitudes and beliefs, as well as expectations of future events and outcomes, are major determinants of health-related behaviour (Gebhardt \& Maes, 2001; Stroebe, 2000).

While there seems to be no lack of health belief models in the literature, the question arises as to which of the many theories that exist is most precise in explaining health-related behaviour? This question is important because it bears directly on the issue of theoretical ex- planatory efficacy, that is, which health behaviour theory provides the best theoretical foundation for framing intervention strategies that can best motivate individuals to alter their maladaptive behaviours. Meta-analyses of the research findings obtained from these health belief models point to both the theory of planned behaviour and the protection motivation theory as the most efficacious in explaining health-related behaviours. More specifically, meta-analyses of the HBM (Janz \& Becker, 1984; Harrison, Mullen, \& Green, 1992), the SCT (Stone, 1999), and the TTM (Michie \& Abraham, 2004; Brawley \& CulosReed, 2000) have identified serious limitations of these theories, ranging from methodological gaps (HBM: Janz \& Becker, 1984), difficulty in operationalising the theory (SCT: Stone, 1999), to contradictory findings relating to the efficacy of the theory (TTM: Riemsma et al., 2003; Marshall \& Biddle, 2001). While both the TPB and the PMT also have limitations associated with their conceptual framework (see Stroebe, 2000; Sutton, 1997), metaanalyses of these two theories have found that they have been used most successfully to plan and evaluate numerous interventions for many different behaviours, including sexual behaviour, smoking, and exercise, among others (Armitage \& Conner, 2001; Floyd, Prentice-Dunn, \& Rogers, 200). The present study has been designed to evaluate and to compare the explanatory/predictive efficacy of the PMT and TPB in terms of the decision-making processes underlying the intention for, as well as engagement in, obesity-related self-care behaviours.

\section{Protection Motivation Model}

The protection motivation (PM) model (Rogers, 1983) is a threat persuasion model that articulates both the factors and processes involved in the evaluation of health threats. Its utility for understanding and predicting health behaviours lies in its elaboration of the crucial mediating process that links behaviour to antecedent communication stimuli. According to the PM model, health behaviour is affected by two appraisal processes: threat appraisal and coping appraisal. According to Rogers (1984), threat appraisal is influenced by specific beliefs the person holds about his/her vulnerability to a particular disorder and beliefs about the severity of the consequences of the disorder. Coping appraisal is conceptualised as consisting of the two cognitive processes of response-efficacy and selfefficacy. Response-efficacy is the individual's expectancy that carrying out the recommended behaviour can remove the health threat, whereas self-efficacy is the belief in one's ability to execute the recommended courses of action successfully. The resultant protection motivation is a mediating variable whose function is to arouse, sustain, and direct protective health behaviour (Boer \& Seydel, 1996).

Specifically then, the PM model posits the four cognitive appraisal processes (perceived severity, perceived vulnerability, self-efficacy, and response-efficacy) that 
mediate the choice of a coping behaviour. Thus, according to the theory, when an individual faces a threat, that threat communication (fear appeal) initiates cognitive appraisal processes concerning: (a) the noxiousness or severity of the threatening event (perceived severity); (b) the probability of the occurrence of the event (perceived vulnerability); (c) the efficacy of a recommended coping response (response-efficacy); and (d) the belief that one is able to perform the response needed to reduce the threat (selfefficacy). The outcome of these appraisal processes is an intermediate state called protection motivation (Rogers, 1983, 1984). According to the PM model then, to change maladaptive behaviours, people must first detect a threat to their health. Once a threat is perceived, individuals must consider ways to avert the threat posed by continuing the maladaptive behaviour. Threat appraisal is linked to the maladaptive response, with intrinsic and extrinsic rewards increasing the chance for a maladaptive response, while the perceived severity of and vulnerability to the threat decreases the likelihood of a maladaptive response. Coping appraisal is linked to the adaptive response, with response-efficacy and self-efficacy increasing the probability that an adaptive response will be initiated. According to Rogers $(1983,1984)$, fear may occur but is not an essential element in this process and does not influence behaviour. That is, in Rogers' conceptualisation, the emotional component of fear may be aroused by threat appraisal, but it does not have a significant role in the appraisal process. Emotions do not directly influence the adoption of coping behaviours, but they do affect cognitive appraisal, which impacts on behaviour intentions (Ho, Davidson, \& Ghea, 2005; Tanner, Hunt, \& Eppright, 1991).

Figure 1 presents the PM model (Rippetoe \& Rogers, 1987; Rogers, 1983, 1984), representing the structural relations hypothesised to exist between the exogenous protection motivation variables of threat appraisal and coping appraisal, the mediating variables of fear, maladaptive coping, and intention for obesity-related self-care behaviours, and the criterion variable of obesity-related self-care behaviours. The unidirectional arrows leading from both threat and coping appraisal to fear reflect Rogers' (1983) position that while emotion may be initiated by appraisal, it does not have a significant role in the appraisal process. The bidirectional arrows linking fear and maladaptive coping reflect Rippetoe and Rogers' (1987) position that maladaptive coping modes are influenced indirectly by the appraisal processes, with fear and maladaptive coping having reciprocal effects on each other. These structural linkages hypothesised to exist between the PM model's exogenous, mediator, and criterion variables have been tested successfully in previous studies (see Calder, Davidson, \& Ho, 2011; Ho, 2000; Ho et al., 2005).

\section{Theory of Planned Behaviour}

The theory of planned behaviour (TPB) is a psychosocial health model of cognitive processes which seeks to pre- dict/explain behavioural intention (Ajzen, 2006; Ajzen \& Madden, 1986). The central focus of TPB is the intention to perform a particular behaviour. Behavioural intentions are indications of how hard people are willing to try or how much of an effort they are planning to exert, in order to perform the behaviour (Armitage \& Conner, 2001). According to the TPB, three conceptually independent factors determine the level of behavioural intention. The first is the attitude toward the behaviour and refers to beliefs about the consequences of a behaviour that includes outcome beliefs - whether a stated behaviour is likely to have the desired consequence and outcome evaluations and whether one views the stated behaviour positively or negatively. For example, a smoker considering giving up smoking may believe that giving up smoking will result in positive health consequences such as lower likelihood of contracting lung cancer, emphysema, and heart disease. In general, the more favourable the attitude towards the behaviour, the stronger should be the individual's intention to perform it.

The second is termed subjective norm and refers to the perceived social pressure to perform or not to perform the behaviour. Normative beliefs are concerned with the likelihood that specific individuals or groups with whom the individual is motivated to comply will approve or disapprove of the behaviour (Armitage \& Conner, 2001). Therefore, normative beliefs are the perceived expectations and social pressures from important persons such as family members and friends. These beliefs, combined with an individual's motivation to comply with the wishes of important people in their lives, determine the subjective norm (Hausenblas, Carron, \& Mack, 1997). Thus, if the individual perceives that significant others endorse (or disapprove of) the behaviour, they are more (or less) likely to intend to perform it; for example, 'I need to lose weight because my mother thinks I should lose weight' (Baker, Little, \& Brownell, 2003).

The third determinant is the degree of perceived behavioural control, which refers to the perceived ease or difficulty of performing the behaviour.

Actual control. As a general rule, the stronger the intention to engage in a behaviour, the more likely should be its performance. It is also clear that a behavioural intention can be translated into behaviour only if the behaviour in question is under volitional control, that is, the person has the ability to perform or not perform that behaviour. Although some behaviours may meet this requirement, others depend, at least to some degree, on such non-motivational factors as availability of opportunities and resources (e.g., time, money, skills, help from others). Collectively, these factors represent people's actual control over the behaviour. According to Ajzen (2006) then, intentions would be expected to influence performance to the extent that the person has behavioural control, and performance should increase with behavioural control to the extent that the person is motivated to try. 


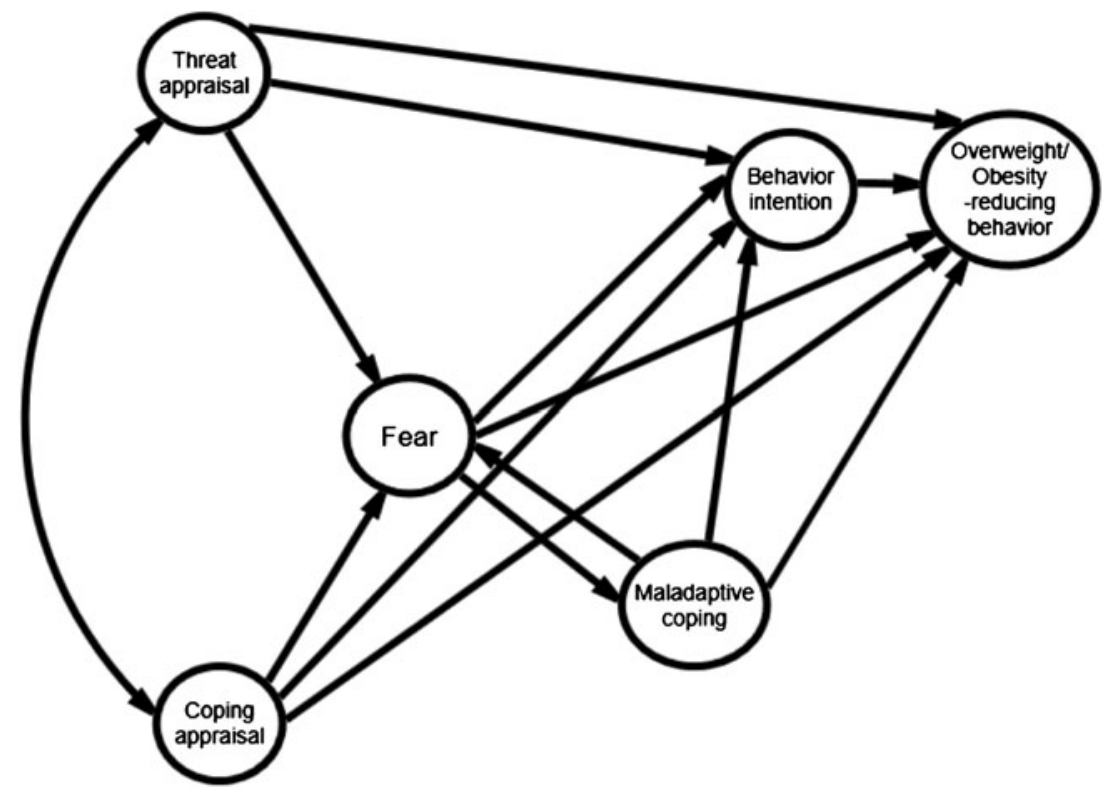

Figure 1

Protection motivation (PM) model.

Perceived control. While the importance of actual control in dictating the likelihood of behavioural achievement is self-evident, of greater psychological interest is the perception of behavioural control and its impact on intentions and actions. Perceived behavioural control refers to people's perception of the ease or difficulty of performing the behaviour of interest. According to Ajzen (2006), perceived control is most compatible with Bandura's (1982) concept of self-efficacy, which is concerned with a person's confidence that he/she has the ability to execute a particular behaviour to bring about the desired outcome. Based on this framework, perceived behavioural control, together with behavioural intention, can be used to predict behavioural achievement. Ajzen (2006) offered two rationales for this hypothesis. First, by holding intention constant, the effort expended to bring a course of behaviour to a successful conclusion is likely to increase with perceived behavioural control. For example, two individuals may have equally strong intentions to learn to drive, and both try to do so. However, the person who is confident that he can master this activity is more likely to persevere and succeed than is the person who doubts his ability. Second, the hypothesised link between perceived behavioural control and behavioural achievement is based on the expectation that perceived behavioural control can often be used as a substitute for a measure of actual control. Under conditions where actual personal control is impossible (e.g., a person who suffers from kidney failure), then perceived behavioural control may offer the opportunity for action, as long as the perceived control is realistic. Perceived control may not be particularly realistic when a person has relatively little information about the behaviour or when necessary resources are unavailable. Under these condi- tions, perceived behavioural control may not be effective in predicting behaviour. However, to the extent that perceived control is realistic, it can be used to predict the likelihood of a successful behavioural attempt (Ajzen, 1985).

As a general rule then, the theory of planned behaviour predicts that the more favourable the attitude and subjective norm with respect to a behaviour, and the greater the perceived behavioural control, the stronger should be an individual's intention to perform the behaviour under consideration. Take the intention to lose weight as an example. If an overweight person believes that losing weight is a worthwhile behaviour (attitude), if members of the person's family actively encourage the person to lose weight (subjective norm), and if the person believes (or has the confidence) that he can follow a regimen of diet and physical exercise programs (perceived behavioural control), then the person's intention to perform the necessary behaviours to lose weight should be strong.

Figure 2 presents the TPB model, representing the structural relations hypothesised to exist between the exogenous variables of attitude, subjective norm, and perceived behavioural control, the mediating variable of behavioural intention, and the criterion variable of obesity-related self-care behaviours. According to the TPB model, attitudes, subjective norms, and perceived control jointly influence intention such that the more positive the attitude and subjective norm and the stronger the perceived control, the greater the intention of the individual to perform the behaviour. The unidirectional arrows leading from attitude, subjective norm, and perceived behavioural control to intention reflect Ajzen's (1988) view that behavioural intention is a direct function of the joint influences of these three considerations. The arrow 


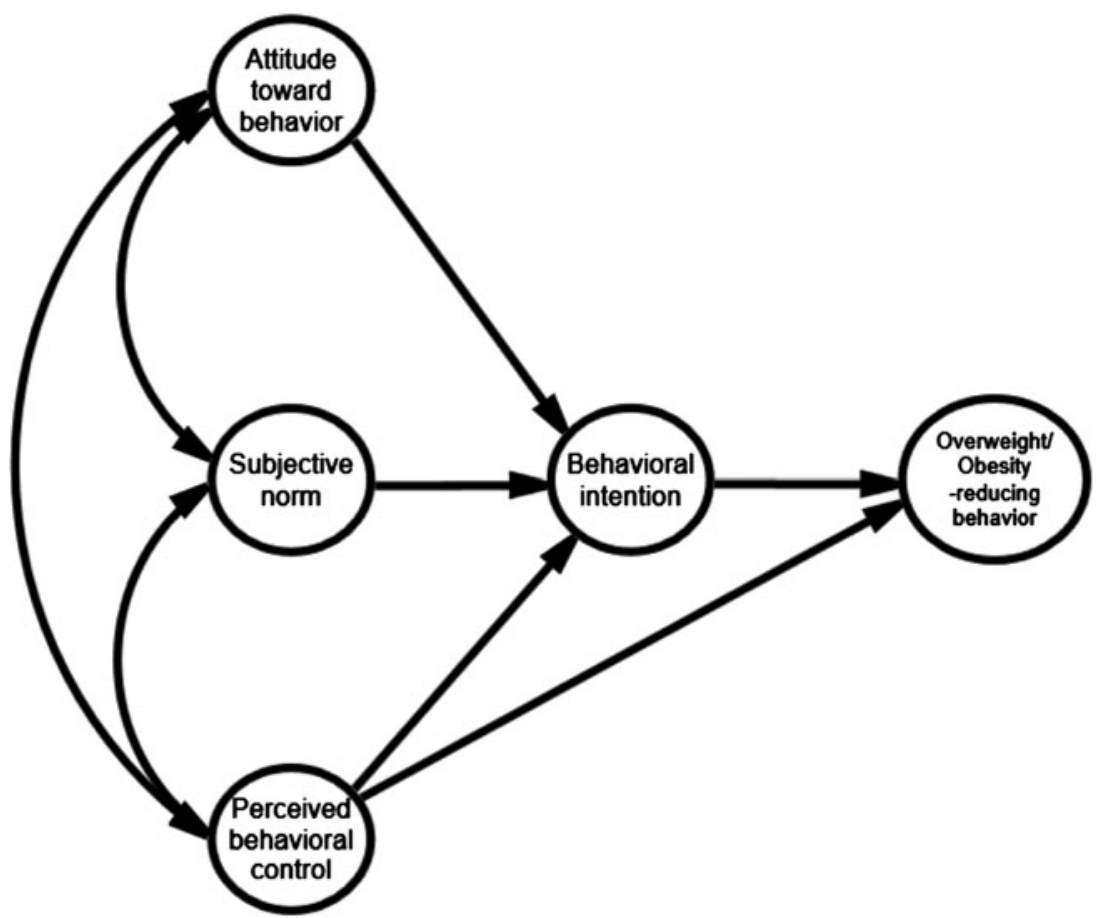

Figure 2

Theory of planned behaviour (TPB) model.

linking intention with behaviour is in line with the theory's suggestion that, as a general rule, the stronger the intention to engage in a behaviour, the more likely should be its performance.

\section{Gender Differences}

There are clearly gender differences in being overweight and obese. In Thailand, these differences are reflected in statistics showing that not only are there more females being classified as overweight and obese than males but that the incidence of this condition is increasing at a much higher rate for females than for males. Information presented by the WHO Global Infobase (2010) for Thai people older than 15 years in 2010 showed that the prevalence of overweight for Thai males and females was $28.3 \%$ and $39.9 \%$ respectively, and that the prevalence of obesity for Thai males and females was $2.6 \%$ and $11.1 \%$, respectively. These statistics show that more females are overweight and obese than males in Thailand. These findings are somewhat consistent with those obtained from other Asian countries (WHO Global Infobase, 2010). For example, in India, the prevalence of overweight for males was higher (20.1\%) than for females (18.1\%); however, the prevalence of obesity was higher for females (2\%) than for males (1.7\%). In Malaysia, the prevalence of both overweight and obesity was higher for females $(42.2 \%$ and $11 \%$, respectively) than for males ( $23 \%$ and $1.7 \%$, respectively). Only in China are the trends clearly reversed, with the prevalence of both overweight and obesity higher for Chi- nese males ( $45 \%$ and $4.1 \%$ respectively) than for Chinese females (32\% and $3.6 \%$ respectively). Overall, these findings point to possible differences in the decision-making process that is clearly gender based. A second major aim of the present study, therefore, was to investigate the possible differential decision-making processes of males and females toward both their intention for, as well as their engagement in, obesity-related behaviours.

There is clearly no one theory or model that can explain and predict the full range of overweight/obesityrelated behaviour. Thus, grounded within a number of theoretical frameworks, the present study was designed to identify, evaluate, and compare which health belief model (PM or TPB) would better explain and support the decision-making processes associated with both the intention for and engagement in overweight/obesity-related self-care behaviours. It is hoped that the findings from the present study will contribute to a better understanding of the decision-making processes of Thai males and females that, more often than not, lead to their increased incidence of being overweight and/or obese.

\section{Method}

\section{Participants and Procedure}

A total of 1,100 participants (males: $n=441,40.1 \%$; female: $n=659,59.9 \%$ ) from the Bangkok metropolitan area, Thailand, volunteered to fill in the study's questionnaire. Their ages ranged from 18 years to 42 years or older, with a median age between 18 to 21 years. Potential 
participants were approached and informed of the general nature of the study, that is, to investigate people's attitudes toward overweight/obesity. Participants were then invited to fill in the study's questionnaire. They were also informed that they could withdraw from filling in the questionnaire at any time; no names would be recorded to guarantee the participants' anonymity and the data collected would only be used for the purposes of this study and only by the researchers.

\section{Materials}

This study employed a self-administered Likert-type rating questionnaire comprising five sections. Section 1 consisted of items written to elicit the participants' demographic information relating to gender, age, nationality, weight, height, and educational level.

Section 2 consisted of 36 items adapted from the Ho et al. (2005) and Calder et al. (2011) studies to measure the protection motivation variables of maladaptive coping, the perceived severity of being overweight/obese, the perceived risk of the threat of being overweight/obese, self-efficacy, response-efficacy, and the emotion of fear. It should be noted that that the adoption of these items to represent the protection motivation constructs was based on both the demonstrated reliability of these PM items as well as the demonstrated construct validity of the PM factors via multi-group confirmatory factor analysis (Ho et al., 2005; Calder et al., 2011). Sample items include the following: maladaptive coping (six items; sample item - 'Most obese people are unlikely to get obesityrelated diseases if there is no history of these diseases in their families'), the perceived severity of being overweight/obese (six items; sample item - 'Failure to control one's weight can lead to death from obesity-related health problems; e.g., heart disease, Type II diabetes, heart attack'), the perceived risk of the threat of being overweight/obese (six items; sample item — 'Failure to monitor one's weight regularly will increase the risk of serious obesity-related health problems'), self-efficacy (six items; sample item - 'I believe I have the ability to control my weight'), response-efficacy (six items: sample item — 'A nutritious diet is effective in reducing the risk of being overweight and its associated health problems'), and the emotion of fear (six items: sample item — 'I am afraid of dying prematurely from obesity-related diseases'). All 36 'protection motivation' items were rated on a 6-point scale ranging from $1=$ strongly disagree to $6=$ strongly agree, with high scores indicating high evaluations of maladaptive coping, perceived severity, risk, self-efficacy, responseefficacy, and fear.

Section 3 consisted of eight items designed to measure overweight- and or obesity-related behaviours. Of these eight items, five measured self-care (i.e., obesityreducing) behaviours (sample item - 'How often do you engage in an activity to manage your weight (e.g., walk, jog, diet)?' The remaining three items were de- signed to measure health-risk (i.e., obesity-inducing) behaviours (sample item - 'How often do you drink alcoholic beverages?'). All eight items were rated on an 8-point scale with high scores reflecting an increase in health-care (obesity-reducing) behaviours and health-risk (obesityinducing) behaviours. The three health risk items were reverse-scored prior to analysis such that for all eight items, high scores indicated high frequency of engagement in overweight/obesity-related self-care behaviours.

Section 4 consisted of eight items designed to measure the behavioural intention associated with the eight obesity-reducing and obesity-related behaviours listed in Section 3: aerobic and non-aerobic exercise, alcohol consumption, eating a healthy diet, and sedentary lifestyle. Of these eight items, five measured self-care (i.e., obesityreducing) intention (sample item - 'I intend to engage in an activity to manage my weight (e.g., walk, jog, diet'). The remaining three items were designed to measure healthrisk (i.e., obesity-inducing) behaviour intentions (sample item - 'I do not intend to cut down on my drinking of alcoholic beverages'). All eight items were rated on a 6 -point scale ranging from $1=$ very unlikely to $6=$ very likely, with high scores indicating high intention to adopt self-care (obesity-reducing) behaviour and highrisk (obesity-inducing) behaviours. The three health risk items were reverse-scored prior to analysis such that for all eight items, high scores indicated strong intention to engage in overweight/obesity-related self-care behaviours.

Section 5 consisted of 18 items written to measure the three TPB factors of attitude ( 6 items), subjective norm (6 items), and perceived behaviour control (6 items). The six items measuring attitude (e.g., 'For me, exercising for at least 20 minutes three times a week to control my weight in the next three months would be: ...') were rated on 6-point scales ranging from $1=$ very bad/very unpleasant/very unimportant to $6=$ very good/very pleasant/very important, with high scores indicating a positive attitude towards the targeted behaviour. The other 12 items measuring subjective norm (e.g., 'Most people who are important to me want me to control my weight') and perceived behaviour control (e.g., 'I am confident that I can control my weight every day for the next three months') were also rated on a 6-point scales ranging from $1=$ strongly disagree to $6=$ strongly agree, with high scores indicating strong perception of subjective norms and strong perceived behaviour control.

\section{Results}

\section{Evaluation and Comparison of the PM and TPB Models}

The fit of the PM and TPB path models posited to represent the hypothesised direct and indirect structural relationships between (1) the PM variables of threat appraisal, coping appraisal, maladaptive coping, fear, health care intention, and health care behaviour, and (2) the TPB variables of attitude, subjective norm, perceived control, health care intention, and health care behaviour, was 
Table 1

Chi-Square Goodness-of-Fit Values, Incremental Fit Indices (NFI, IFI, TLI, CFI), Akaike Information Criterion (AIC), Parsimony Normed Fit Index (PNFI), Root Mean Square Error of Approximation (RMSEA), and Model Comparison

\begin{tabular}{lllllllllll}
\hline Model & $\chi^{2}(N=1,100)$ & $d f$ & $p$ & NFI & IFI & TLI & CFI & PNFI & AIC & RMSEA \\
\hline Model A: PM model & 446.51 & 90 & $<.01$ & 0.95 & 0.96 & 0.94 & 0.96 & 0.709 & 538.51 & 0.06 \\
Model B: TPB model & 295.69 & 82 & $<.01$ & 0.96 & 0.97 & 0.97 & 0.97 & 0.754 & 371.69 & 0.05 \\
$\begin{array}{l}\text { Model comparison } \\
\text { Model A vs. Model B }\end{array}$ & 150.82 & 8 & $<.01$ & 0.01 & 0.01 & 0.03 & 0.01 & 0.045 & 166.82 \\
\hline
\end{tabular}

tested via structural equation modelling. This statistical technique analysed the covariance matrix generated from the models' measurement variables. Table 1 presents the results of this analysis.

\section{PM Model}

Although the overall chi-square value was significant, $\chi^{2}(d f=90)=446.51, p<.01$, the incremental fit indices (NFI, IFI, TLI, CFI) were all above 0.90 (range: 0.940.96 ). These fit indices indicated that the model provided a good fit relative to a null or independence model (i.e., the posited model represented between $94 \%$ to $96 \%$ improvement in fit over the null or independence model), and supported the hypothesised structure of the posited path model. The RMSEA value of 0.06 is also within the range suggested by Browne and Cudeck (1993) and indicates that the model fits the population covariance matrix well. The model also yielded a parsimony normed fit index (PNFI) of 0.709 and an Akaike information criterion (AIC) value of 538.51. Both the PNFI and the AIC are used for comparing the goodness-of-fit of competing models.

\section{TPB Model}

The TPB model was also tested via structural equation modelling. Although the overall chi-square value was significant, $\chi^{2}(d f=82)=295.69, p<.01$, the incremental fit indices (NFI, IFI, TLI, CFI) were all above 0.90 (range: $0.96-0.97$ ). These fit indices indicated that the model provided a good fit relative to a null or independence model (i.e., the posited model represented between $96 \%$ to $97 \%$ improvement in fit over the null or independence model), and support the hypothesised structure of the posited path model. The RMSEA value of 0.05 is also within the range suggested by Browne and Cudeck (1993) and indicates that the model fits the population covariance matrix well. The model also yielded a PNFI of 0.754 and an AIC value of 371.69 .

\section{Comparison of the Goodness-of-Fit of the PM and TPB Models}

Although the overall structure of these two models are different (they reflect differences in the way the cognitive variables of maladaptive coping, threat appraisal, coping appraisal, fear, attitude, subjective norm, and perceived control are hypothesised to operate in the PM and TPB models), they are based on the same covariance matrix (generated from the same sample). Thus, with different degrees of freedom, direct comparison of these two models is possible.

While the results showed that both the PM and TPB models fitted the covariance matrix well relative to the null model, direct model comparison indicated that the TPB model fitted the data significantly better than the PM model, $\chi^{2}(d f=8)=150.82, p<01$. The comparison results suggest that the TPB model may provide a better representation than the PM model of the way people make decisions about their intention for as well as their engagement in self-care overweight/obesity-reducing behaviours. The goodness-of-fit of competing models can also be compared by means of the PNFI and the AIC measure (Akaike, 1987). In evaluating hypothesised models, the PNFI takes into account model parsimony, that is, achieving a higher degree of fit per degree of freedom used. A higher PNFI value indicates a model that is more parsimonious. The AIC takes into account both model parsimony and model fit. Simple models that fit well receive low scores, whereas poorly fitting models get high scores. A small AIC generally occurs when small chi-square values are achieved with fewer estimated coefficients. This shows not only a good fit of observed versus predicted co-variances but also a model not prone to 'over-fitting' (Jöreskog, 1993). Comparing the PNFI and AIC measures for the PM and TPB models, it is evident that the TPB model provided a higher PNFI value (.754) as well as a lower AIC value (371.69) than the PM model (PNFI = .709 ; $\mathrm{AIC}=538.51)$. These parsimony fit indices indicate that the TPB model is both more parsimonious and better fitting than the PM model.

\section{Multi-Group Path Analysis: Evaluation of the Consistency of the TPB Model Across the Two Groups of Male and Female Participants}

A multi-group path analysis was conducted to investigate whether the pattern of structural relationships represented in the TPB path model presented in Figure 2 follows the same dynamics for the two groups of male and female participants. The following sequence of hypotheses was developed for analysing group differences in this model: (1) path coefficients have the same pattern for the two groups of respondents, and (2) path coefficients are identical for the two groups of participants.

In determining the consistency of the model across groups, the model was first specified to have the same pattern of path coefficients for both groups, but 


\begin{tabular}{|c|c|c|c|c|c|c|c|c|}
\hline Model & $\chi^{2}(N=1,100)$ & $d f$ & $p$ & NFI & IFI & TLI & $\mathrm{CFI}$ & AIC \\
\hline Null model & $8,613.612$ & 210 & $<.001$ & .00 & 0.00 & 0.00 & 0.00 & $8,673.612$ \\
\hline Model A: Unconstrained (variant) model & 393.658 & 168 & $<.001$ & .95 & 0.97 & 0.97 & 0.97 & 537.658 \\
\hline $\begin{array}{l}\text { Model B: Constrained (invariant) model } \\
\text { Model comparison }\end{array}$ & 394.819 & 172 & $<.001$ & .95 & 0.97 & 0.97 & 0.97 & 530.819 \\
\hline Model A vs. Model B & 1.161 & 4 & $>.05$ & .00 & 0.00 & 0.00 & 0.00 & 6.839 \\
\hline
\end{tabular}

allowed these coefficients to be estimated separately within each group. For this unconstrained/variant model, $\chi^{2}(d f=168)=393.658, p<.001$. The incremental fit indices (NFI, IFI, TLI, CFI) are all above 0.90 (range: 0.950.97). These fit indices indicated that the posited variant model provided a good fit relative to the null or independence model, and support the hypothesised structure of the model posited for the male and female participants.

The preceding model specified the same pattern of fixed and free parameters for the two groups, but estimated these parameters separately within each group. In order to test the consistency of the model across groups, the model was respecified to have the path coefficients constrained to be invariant across the two groups of participants. Results from the analysis indicated that this constrained/invariant model also fitted the data well, $\chi^{2}(d f=172)=394.819$, $p<.001$; the incremental fit indices of NFI, IFI, TLI, CFI ranged from 0.95 to 0.97 . Results of a chi-square difference test comparing this model with one that simply specified the same pattern of path coefficients indicated no significant difference in fit between the variant and invariant models, $\chi^{2}(d f=4)=1.161, p>.05$. This suggests that the hypothesised pattern of structural path relationships (between the exogenous, mediator, and criterion variables) posited on the basis of the TPB to represent the decisionmaking processes in relation to overweight/obesity-related health care behaviours operate similarly for the male and female participants.

The goodness-of-fit of competing models can also be compared by means of the AIC measure (Akaike, 1987). In evaluating hypothesised models, this measure takes into account both model parsimony (i.e., achieving a higher degree of fit per degree of freedom used) and model fit. Simple models that fit well receive low scores, whereas poorly fitting models get high scores. Comparing the AIC measures for the constrained (invariant) model (394.819) and the unconstrained (variant) model (393.658), it is evident that there is very little difference in the magnitude of the scores, indicating that the constrained/invariant model and the unconstrained/variant model are equally parsimonious and good-fitting. Table 2 presents the goodness-offit indices for both these models, together with the model comparison statistics.

The significant standardised path coefficients for the TPB path model for the male and female participants are shown in Figures 3 and 4.

\section{Standardised Regression Path Coefficients}

As shown in Figure 3, for the male participants, (1) the more positive their attitude toward overweight/obesity reducing behaviours (exercising, eating healthily) and the higher their perception of personal control over their ability to control their weight, the higher their reported intention to engage in overweight/obesity-reducing health care behaviours ( $\beta=.23$ and $\beta=.52$ respectively); and (2) the higher their reported intention, the higher their reported frequency of engagement in overweight/obesity-reducing health care behaviours $(\beta=.45)$.

From Figure 4 it can be seen that the structural path relationships between the TPB model's exogenous, mediator, and criterion variables for the female participants are highly similar to those found for the male participants. This is not unexpected given that direct model comparison conducted previously showed no significant difference in model-fit for the two groups of participants. Thus, similar to their male counterparts, for the female participants, (1) the more positive their attitude toward overweight/obesity reducing behaviours (exercising, eating healthily), the higher their perception of personal control over their ability to control their weight, and the stronger their perceived social pressure to engage in overweight/obesity reducing behaviours, the higher their reported intention to engage in overweight/obesityreducing health care behaviours $(\beta=.22, \beta=.50$, and $\beta=$ .14 respectively); and (2) the higher their reported intention, the higher their reported frequency of engagement in overweight/obesity-reducing health care behaviours $(\beta=.43)$.

\section{Residuals (Unexplained Variance)}

Figures 3 and 4 also report the standardised residual for each endogenous variable in the model for male and female participants. These coefficients provide an estimate of the proportion of variance in each endogenous variable not predicted by the model. Alternatively, subtracting these values from 1.00 indicates the proportion of variance predicted by the model. These coefficients indicated that for both the male and female participants, the three TPB factors of attitudes, subjective norm, and perceived control accounted for a similar $55 \%$ of the variance in the TPB factor of 'intention to engage in overweight/obesity-reducing health care behaviours'. The entire model (i.e., the four 


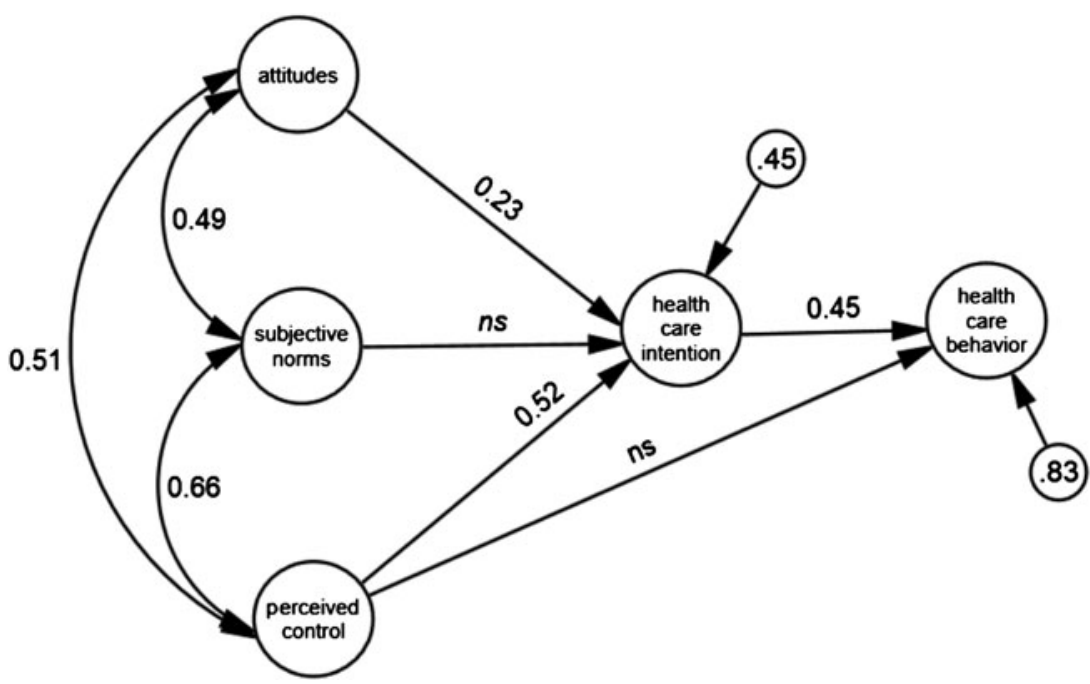

Figure 3

TPB path model for male participants together with the model's significant path coefficients. Note: $n s=$ not significant, $p>.05$.

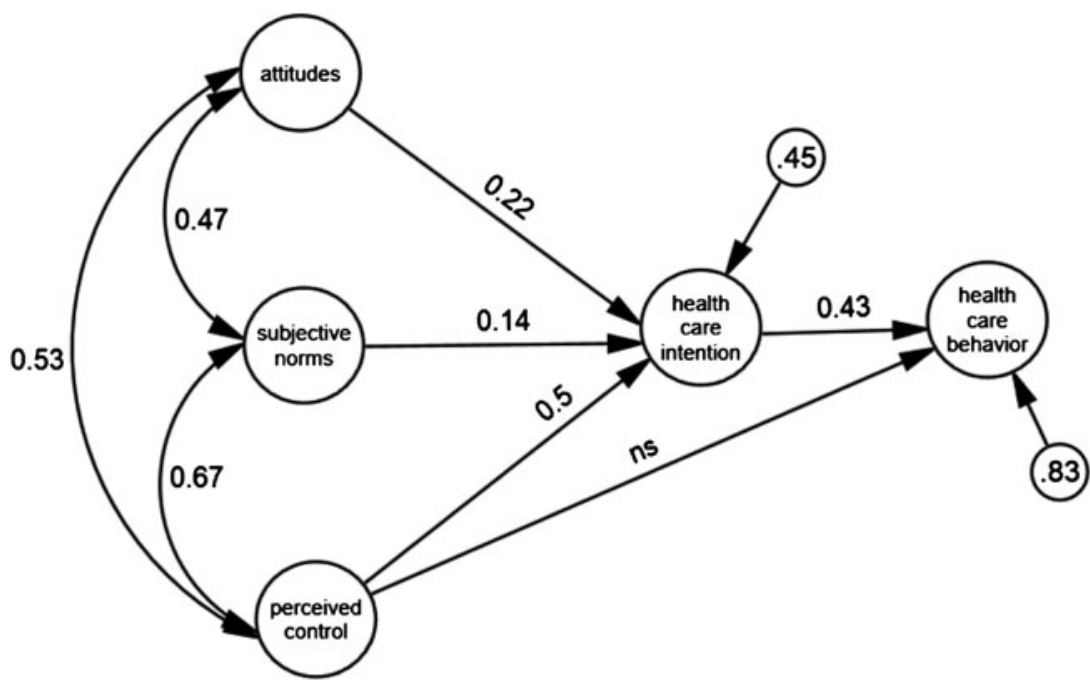

\section{Figure 4}

TPB path model for female participants together with the model's significant path coefficients. Note: $n s=$ not significant, $p>.05$.

TPB factors of attitudes, subjective norm, perceived control and behavioural intention) also accounted for a similar $17 \%$ of the variance in the male and female participants' reported frequency of engagement in overweight/obesityreducing health care behaviours.

\section{Discussion}

The present study was designed to identify, evaluate, and compare which health belief model (PM or TPB) would better explain and support the decision-making processes associated with both the intention for and engagement in overweight/obesity-reducing behaviours. As elaborated earlier, both theoretical models are motivational models that hold the assumption that 'drive' is sufficient for successful behavioural enactment and therefore focus on the motivational factors that determine performance. When applied to the explanation/prediction of health-related behaviours, both models share the commonality of identifying factors that can best explain and/or predict the likelihood of engaging in health-related behaviours. However, they differ in terms of the factors identified, and in particular, the theoretical rationale employed to support the cognitive (decision-making) processes that link these factors in the prediction of and intervention in health-related behaviours (Armitage, 2005; Petermann, 2010; Schifter \& Ajzen, 1985). For example, based on Lazarus' theory of cognitive appraisal (Lazarus, 1966, 1968, 1991), the PM model focuses on the cognitive appraisal processes of threat appraisal and coping appraisal when confronted with a health threat communication. In contrast, the TPB model is based on the assumption that attitudes, 
subjective norms, and perceived behavioural control are important predictive factors of intention to engage in behaviours, and that intention is the best predictor of a person's behaviour (Ajzen, 2006; Armitage \& Conner, 2001).

While these two theories have been widely adopted as theoretical frameworks for the prediction of, and intervention in, health-related behaviours such as healthy eating, physical activity/exercise, and weight loss (Armitage, 2005; Petermann, 2010; Schifter \& Ajzen, 1985), the question was raised as to which theory or model can better explain and predict overweight/obesity-related self-care behaviours. The multi-model analysis conducted revealed that the TPB model is both more parsimonious and better fitting than the PM model. These findings support the conclusion that the TPB model is a better representation of the decision-making processes leading to the intention for, as well as the frequency of engaging in, overweight/obesityreducing behaviours than the PM model.

A number of reasons could have accounted for the explanatory efficacy of the TPB model over the PM model. First, the TPB model includes social and environmental factors (subjective norm) in motivating both intention and behaviour, whereas the PM model does not include the social context in its hypothesised appraisal processes (Ogden, 2012). Previous research has found that families and friends - in particular, their attitudes and perceptions - are influential in reducing the risk of being overweight and obese (Babooram, Mullan, \& Sharpe, 2011; Gronbaek, 2008; Wang, 2011). Similarly, a recent Thai-based study found that classmates, family members, and caregivers influenced Thai children's healthy eating behaviours; and that furthermore, advertising, snack packaging, and marketing techniques influence their food choices (Korwanich, Sheiham, Srisuphan, \& Srisilapanan, 2007). These findings suggest that social and environmental factors (e.g., family, friends, advertisements) play significant roles in people's decision-making processes regarding overweight/obesity-reducing behaviours.

Second, the TPB model, unlike the PM model, incorporates attitude as an important determinant of healthrelated intention and behaviour. Previous research found that attitudes predict the intention to eat healthily and to be physically active; for example, people who believe that healthy food tastes worse are less likely to report healthy eating behaviour. Attitude also mediates the relationship between norms and intentions for healthy eating and activity. For example, people who perceive that their eating and activity behaviours are not important to their peers and families, or that their friends and families are not very health-conscious about eating and physical activities, are less likely to have positive attitudes about healthy eating and activity. Such negative attitudes are often associated with lower intention to eat healthily and to be physically active (Baker et al., 2003).

Third, the PM model incorporates the cognitive process of threat appraisal when confronted with a health threat communication; threat appraisal, however, may not be perceived as particularly relevant by young adults when considering the condition of being overweight/obese (Rickett, Orbell, \& Sheeran, 2006). The median age of the participants in the current study was within the range of 18 to 21 years. At this young age, the thought of suffering the pain and discomfort from overweight/obesity-related diseases (e.g., coronary heart disease, cancer, stroke, arthritis) is not only alien to them but that these symptoms are associated only with older people; in other words, the belief that they are invulnerable to health-related diseases overrides the perceived threat posed by their own health-related behaviours (Hubert, Feinleib, McNamara, \& Castelli, 1983). Such an age-related 'invulnerability' attitude is supported by the finding that younger women are less likely to be aware that heart disease is the leading cause of death among women than their older counterparts (Mochari-Greenberger, Miller, \& Mosca, 2012). Given such an invulnerability attitude toward health-related issues, threat appraisal within the PM model appears to be less than relevant for the study's young adults in their evaluation of the perceived severity of and their vulnerability to overweight/obesity-related diseases.

As stated earlier, statistics show that more females are overweight and obese than males in Thailand, which suggest that there may be important gender differences in their decision-making processes associated with their obesity-related intentions and behaviours. However, the test of model-invariance via multi-group path analysis in the present study yielded no significant difference in fit between the variant and invariant model, which suggests that the hypothesised pattern of structural path relationships (between the exogenous, mediator, and criterion variables) posited on the basis of the TPB to represent the decision-making processes in relation to self-care overweight/obesity-reducing behaviours operate similarly for the male and female participants. This similarity is reflected in the TPB's structural path relationships, which are highly similar for the male and female participants. For example, for both the male and female participants, the more positive their attitude toward overweight/obesity reducing behaviours (exercising, eating healthily) and the higher their perception of personal control over their ability to control their weight, the higher their reported intention to engage in overweight/obesity-reducing health care behaviours, and subsequently the higher their reported frequency of engagement in overweight/obesityreducing health care behaviours. It was also found that for the female participants only, the stronger their perceived social pressure to engage in overweight/obesity reducing behaviours, the higher their reported intention to engage in such positive health behaviours, and subsequently the higher their reported frequency of engagement in overweight/obesity-reducing health care behaviours. Together, these findings suggest that health professionals in the business of helping both males and females to control their weight should focus more on enhancing their positive attitude toward overweight/obesity reducing 
behaviours (such as exercising, eating healthily) as well as their perception of personal control over their ability to control their weight. For example, health professionals can help those who lack the motivation to exercise to change their attitude and belief by reinforcing the idea that engaging in regular exercise is not difficult and that this activity can actually be effective in helping them control their weight. Through the development of a more positive attitude towards overweight and/or obesity-reducing behaviours, health professionals can help individuals, both males and females, understand and accept that engaging in regular exercise is good, pleasant, and important to their health. Interestingly, the only obtained gender difference was the significant influence of subjective norms on the female participants' intention to engage in positive health behaviours. For the male participants, their perceived social pressure from significant others was not found to exert any significant influence on their intention to engage in positive health behaviours. This obtained gender difference is not unexpected given that past research findings have shown that both men and women expressed beliefs that women are more socially oriented and family-focused than men (Butler, 1999; Ross, 2011). As such, females experience more pressure from significant others to conform and therefore their weight control effort should also focus on the perceived social pressure from significant others (parents, spouses, friends) to engage in overweight/obesity reducing behaviours.

Like any empirical study, the present study carried with it a number of limitations. First, the study employed a cross-sectional design in which the posited path models were tested at only one point in time via structural equation modelling (SEM). SEM is essentially a regression technique and, as such, the models' path coefficients were computed on the basis of the covariances between the models' measurement variables. Given the cross-sectional design of the study and the correlational nature of the results, no definitive conclusions can be drawn about the 'causal sequential effects' (both direct and indirect) between the models' exogenous, mediator, and criterion variables.

Second, and perhaps most importantly, the cognitive processes hypothesised by the PM and the TPB models may not directly predict the amount of overweight/obesity-reducing behaviours that will occur. While retrospective behaviours were measured in the present study, what was predicted was the potential for the respondents to hold intentions to act, rather than the action itself. As Weinstein (1988) has pointed out, predicting intentions does not permit a researcher to draw definitive conclusions about what percentage of the population will act to protect the self from a health threat, or the extent of the behavioural changes. While attitudinal approaches to preventive health behaviour are still important in raising people's consciousness about the dangers associated with certain beliefs, future approaches should focus on the behaviours themselves and on the situa- tional cues that maintain these behaviours, independent of attitudes.

With the above limitations in mind, the findings from the present study carry a number of important implications for understanding the decision-making processes underlying the participants' intention for, as well as their engagement in, overweight/obesity-reducing behaviours. First, the overall findings obtained from the evaluation of and comparison between the two cognitive models fit well with the growing body of literature that point to the TPB as a potent theoretical framework for explaining and predicting intentions and behaviours. Compared to the PM model, the TPB clearly offered a better representation of the decision-making processes that underlie overweight/obesity-reducing behaviours. These findings point to the efficacy of TPB factors, such as attitudes, subjective norms, perceived control, and intentions, over the cognitive appraisal processes (threat appraisal and coping appraisal) expounded by the PM model in predicting high-risk and health-care behaviours. Health practitioners can employ these findings when developing intervention strategies designed to train their clients to hold more salient positive attitudes toward overweight/obesity reducing behaviours, as well as to inculcate a greater sense of personal control over their ability to control their weight. For females only, intervention effort should also emphasise the importance of social norms, and in particular, the advice provided by significant others to conform to good health practices. Persuasive communication was suggested by Ajzen and Fishbein (1980) as a method to change beliefs, and other research (Chatzisarantis \& Hagger, 2005) has demonstrated that persuasive messages that incorporate the TPB factors of positive health attitudes, advice from significant others, and perception of personal control can influence intention, which directly influences behaviour. Thus, intervention strategies based on the persuasive communication factors championed by the TPB is likely to result in positive health behaviour change.

Second, the present study employed a purely quantitative approach to investigate the motivation to engage in overweight/obesity-related behaviours. While such an approach offers clearly operationalised variables and quantifiable/measurable outcomes, it has been recently suggested that reducing motivation to its quantitative dimension could be an important limiting factor in current overweight/obesity intervention research (Teixeira, Silva, Mata, Palmeira, \& Markland, 2012). As pointed out by these authors, encountering different events (e.g., suffering chest pain, receiving advice from a doctor, getting tired easily) can lead people to initiate the same course of action, such as going on a diet, potentially with no measurable difference in how much they want to lose weight. Similarly, motives such as the desire to improve physical attractiveness or reduce body size/shape dissatisfaction may carry different implications during a weight-loss treatment program from, say, sticking with a prescribed diet primarily to improve health or to encourage family members and 
friends to eat healthily. Moreover, the source and nature of motivation for weight loss could change markedly during the course of treatment. Although a quantitative approach to the study of motives allows for clear and empiricalbased measurable outcomes, there is also the need to go beyond considering the amount of a person's motivational impulse and to consider the quality of the motives behind the weight-loss decision. For example, what is the personal meaning (or meanings) associated with exercising regularly, eating healthily, or losing a certain amount of weight? Why do some people become demotivated and others do not when it comes to the maintenance of their desired weight? Why do some participants abandon their weight-loss efforts when, despite improvements in their lifestyle and also their health, they did not lose as much weight as they had planned? What makes the difference between intrinsic and extrinsic forms of motivation and associated weight-loss behaviours? A review of the obesity-related literature will show that the bulk of the motivation research for obesity behaviour change has almost exclusively employed the quantitative methodology that typically only focuses on the 'onedimensional' quantitative measurement of the achieved outcome. According to Patrick, Gorin, and Williams (2010), a more sophisticated examination of the consequences of differences in the quality of motivation could contribute to a better understanding of successful weight control and eventually aid in the design of more effective interventions.

\section{Conclusion}

Given the worldwide epidemic of overweight and obesity, the present study was designed to investigate the decision-making processes underlying the intention to and engagement in self-care overweight/obesity-reducing behaviours. The overall findings were compatible with the notion that psychological motives are among the key predictors of the decision of whether or not to engage in overweight/obesity-related behaviours. In particular, the finding that the TPB offered a better representation of and provided a more potent theoretical framework than the PM model in explaining the decision-making processes underlying overweight/obesity-reducing behaviours, points to the efficacy of the factors of attitudes, subjective norms, perceived control, and intentions in motivating the decision to engage in health-care behaviours. The superiority in explanatory power of these cognitive factors over the cognitive appraisal factors (perceived severity, perceived risk, self-efficacy, response-efficacy) championed by the PM model, suggests that overall success of intervention programs (such as weight-reduction programs) can be enhanced by incorporating these TPB factors in their design. More and better studies employing these motives in overweight/obese persons are suggested for future investigation to provide the needed experimental evidence that will further our understanding of the role of motivation, and especially self-motivation, in the long-term and worldwide battle against overweight and obesity.

\section{References}

Ajzen, I. (1985). From intentions to actions: A theory of planned behavior. In J. Kuhl \& J. Beckman (Eds.), Action-control: From cognition to behavior (pp. 11-39). Heidelberg: Springer.

Ajzen, I. (1988). Attitudes, personality, and behavior. Homewood, IL: Dorsey Press.

Ajzen, I. (2006). Constructing a theory of planned behavior questionnaire. TPB question construction. Retrieved October 11, 2011, from http://people.umass.edu/aizen/pdf/tpb. measurement.pdf

Ajzen, I., \& Fishbein, M. (1980). Understanding attitudes and predicting social behavior. Englewood Cliffs, NJ: PrenticeHall.

Ajzen, I., \& Madden, T.J. (1986). Prediction of goal-directed behavior: Attitudes, intentions, and perceived behavioral control. Journal of Experimental Social Psychology, 22, 453-474.

Akaike, H. (1987). Factor analysis and AIC. Psychometrika, 52, 317-332.

Armitage, C.J., \& Conner, M. (2001). Efficacy of the theory of planned behavior: A meta-analytic review. British Journal of Social Psychology, 40, 471-499.

Armitage, C.J. (2005). Can the theory of planned behavior predict the maintenance of physical activity? Health Psychology, 24, 235-245.

Babooram, M., Mullan, B.A., \& Sharpe, L. (2011). Children's perceptions of obesity as explained by the common sense model of illness representation. British Food Journal, 113(2), 234-247

Baker, C.W., Little, T.D., \& Brownell, K.D. (2003). Predicting adolescent eating and activity behaviors: The role of social norms and personal agency. Health Psychology, 22, 189-198.

Bandura, A. (1982). Self-efficacy mechanism in human agency. American Psychologist, 37, 122-147.

Becker, M.H. (1974) The health belief model and personal health behavior. Health Education Monographs, 2, 324-508.

Boer, H., \& Seydel, E.R. (1996). Protection motivation theory. In M. Conner \& P. Norman (Eds.), Predicting health behavior. Buckingham, UK: Open University Press.

Brawley, L.R., \& Culos-Reed, S.N. (2000). Studying adherence to therapeutic regimens: Overview, theories, recommendations. Control Clinical Trials, 21, 156S-163S.

Browne, M.W., \& Cudeck, R. (1993). Alternative ways of assessing model fit. In K.A. Bollen \& J.S. Long (Eds.), Testing structural equation models (pp. 445-455). Newbury Park, CA: Sage.

Butler, J. (1999). Gender trouble: Feminism and the subversion of identity. London and New York: Routledge.

Calder, S.C., Davidson, G.R., \& Ho, R. (2011). Intentions to consume Omega-3 fatty acids: A comparison of protection motivation theory and ordered protection motivation theory. Journal of Dietary Supplements, 8, 115-134. 
Chatzisarantis, N.L.D., \& Hagger, M.S. (2005). Effects of a brief intervention based on the Theory of Planned Behavior on leisure time physical activity participation. Journal of Sport Exercise Psychology, 27, 470-487.

Floyd, D.L., Prentice-Dunn, S., \& Rogers, R.W. (2000). A metaanalysis of research on protection motivation theory. Journal of Applied Social Psychology, 30, 407-429.

Gebhardt, W.A., \& Maes, S. (2001). Integrating socialpsychological frameworks for health behaviour research. American Journal of Health Behavior, 25, 528-536.

Gronbaek, H.N. (2008). We've always eaten healthily: Family narratives about causes of their child's obesity and their motivation for taking action. Nordic Psychology, 60, 183-208.

Harrison, J.A, Mullen, P.D., \& Green, L.W. (1992). A metaanalysis of studies of the health belief model with adults. Health Education Research, 7, 107-116.

Hausenblas, H.A., Carron, A.V., \& Mack, D.E. (1997). Application of the theories of reasoned action and planned behavior to exercise behavior: A meta-analysis. Journal of Sport and Exercise Psychology, 19, 36-51.

Ho, R. (2000). Predicting intention for protective health behaviour: A test of the protection versus the ordered protection motivation model. Australian Journal of Psychology, 52, $110-118$

Ho, R., Davidson, G., \& Ghea, V. (2005). Motives for the adoption of protective health behaviors for men and women: An evaluation of the psychosocial-appraisal health model. Journal of Health Psychology, 10, 373-395.

Hubert, H.B., Feinleib, M., Mcnamara, P.M., \& Castelli, W.P. (1983). Obesity as an independent risk factor for cardiovascular disease: A 26-year follow-up of participants in the Framingham heart study. Circulation, 67, 968-977.

Janz, N.K., \& Becker, M.H. (1984). The health belief model: A decade later. Health Education Quarterly, 11, 1-7.

Jöreskog, K.G. (1993). Testing structural equation models. In K.A. Bollen \& J.S. Long (Eds.), Testing structural equation models (pp. 294-216). Newbury Park, CA: Sage.

Korwanich, K., Sheiham, A., Srisuphan, W., \& Srisilapanan, P. (2007). Opinions of parents, teachers, and school board members regarding healthy eating: A qualitative investigation of lay Thai people's perspectives. Journal of the Medical Association of Thailand, 90, 1014-1020.

Lazarus, R.S. (1966). Psychological stress and the coping process. New York: McGraw-Hill.

Lazarus, R.S. (1968). Emotions and adaptation: Conceptual and empirical relations. In W.J. Arnold (Ed.), Nebraska symposium on motivation (vol. 16, pp. 175-266). Lincoln: University of Nebraska.

Lazarus, R.S. (1991). Cognition and motivation in emotion. American Psychologist, 46, 352-367.

Manson, J.E., \& Bassuk, S.S. (2003). Obesity in the United States: A fresh look at its high toll. Journal of the American Medical Association, 289, 229-230.

Marshall, S.J., \& Biddle, S.J.H. (2001). The transtheoretical model of behaviour change: A meta-analysis of applications to physical activity and exercise. Annual Behavioral Medicine, 23, 229-246.

Michie, S., \& Abraham, C. (2004). Interventions to change health behaviours: Evidence-based or evidence-inspired? Psychological Health, 19, 29-49.

Mochari-Greenberger, H., Miller, K.L., \& Mosca, L. (2012). Racial/ethnic and age difference in women's awareness of heart disease. Journal of Women's Health, 21, 476-480.

Ogden, J. (2012). Health Psychology: A textbook. Maidenhead: Open University Press.

Onis, M., Blossner, M., \& Borghi, E. (2010). Global prevalence and trends of overweight and obesity among preschool children. American Journal of Clinical Nutrition, 92, 12571264 .

Patrick, H., Gorin, A.A., \& Williams, G.C. (2010). Lifestyle change and maintenance in obesity treatment and prevention: A self-determination theory perspective. In L. Dube, A. Bechara, A. Dagher, A. Drewnowski, J. LeBel, P. James, \& R.Y. Yada (Eds.), Obesity prevention: The role of the brain and society on individual behavior (pp. 365-374). New York: Academic Press.

Pesa, J.A., Syre, T.R., \& Jones, E. (2000). Psychosocial differences associated with body weight among female adolescents: The importance of body image. Journal of Adolescent Health, 26, 330-337.

Petermann, P. (2010). An application of protection motivation theory to assess public acceptance and willingness to pay towards personalized food nutrition. Retrieved from http://www.otago.ourarchive.ac.nz/bitstream/handle/ 10523/418/Petermann

Prochaska, J., \& DiClemente, C. (1983). Stages and processes of self-change in smoking: Toward an integrative model of change. Journal of Consulting and Clinical Psychology, 5, 390395.

Rickett, B., Orbell, S., \& Sheeran, P. (2006). Social-cognitive determinants of hoist usage among health care workers. Journal of Occupational Health Psychology, 11, 182-196.

Rippetoe, P.A., \& Rogers, R.W. (1987). Effects of components of protection motivation theory on adaptive and maladaptive coping with a health threat. Journal of Personality and Social Psychology, 52, 596-604.

Riemsma, R.P., Pattenden, J., Bridle, C., Sowden, A.J., Mather, L., Watt, I.S., \& Walker, A. (2003). Systematic review of the effectiveness of stage based interventions to promote smoking cessation. British Medical Journal, 326, 1175-1177.

Rogers, R.W. (1983). Cognitive and physiological processes in attitude change: A revised theory of protection motivation. In J. Cacioppo \& R. Petty (Eds.), Social psychophysiology (pp. 153-176). New York: Guilford Press.

Rogers, R.W. (1984). Changing health-related attitudes and behavior: The role of preventive health psychology. In J.H. Harvey, J.E. Maddux, R.P. McGlynn, \& C.D. Stoltenberg (Eds.), Social perception in clinical and counseling psychology (pp. 291-312). Lubboch, TX: Texas Tech University Press.

Ross, K. (Ed.). (2011). The handbook of gender, sex and media. Malden, MA: Wiley-Blackwell. 
Schifter, D.E., \& Ajzen, I. (1985). Intention, perceived control, and weight loss: An application of the theory of planned behavior. Journal of Personality and Social Psychology, 49, 843-851.

Simon, G.E., Von Korff, M., Saunders, K., Miglioretti, D.L., Crane, P.K., Van Belle, G., \& Kessler, R.C. (2006). Association between obesity and psychiatric disorders in the US adult population. Archives of General Psychiatry, 63, 824830.

Stone, D. (1999). Social cognitive theory. Retrieved March 14, 2006, from http://hsc.usf.edu/ kmbrown/Social_ Cognitive_Theory_Overview.htm

Stroebe, W. (2000). Social psychology and health (2nd ed.). Buckingham, UK: Open University Press.

Sutton, S. (1997). Theory of planned behaviour. In A. Baum, S. Newman, J. Weinman, R. West, \& C. McManus (Eds.), Cambridge handbook of psychology, health and medicine (pp. 177-179). Cambridge, UK: Cambridge University Press.

Tanner, Jr., J.F., Hunt, J.B., \& Eppright, D.R. (1991). The protection motivation model: A normative model of fear appeals. Journal of Marketing, 55, 36-45.

Teixeira, P.J., Silva, M.N., Mata, J., Palmeira, A.J., \& Markland, D. (2012). Motivation, self-determination, and longterm weight control. International Journal of Behavioral Nutrition and Physical Activity, 9, 22. Retrieved from http://www.ijbnpa.org/content/pdf/1479-5868-9-22.pdf
Vander Wal, J.S., \& Thelen, M.H. (2000). Eating and body image concerns among obese and average weight children. Addictive Behaviors, 25, 775778.

Vila, G., Zipper, E., Dabbas, M., Bertrand, C., Robert, J.J., Ricour, C., \& Mouren-Simeoni, M.C. (2004). Mental disorders in obese children and adolescents. Psychosomatic Medicine, 66, 387-394.

Wang, L. (2011). Effects of maternal depression on childhood overweight and obesity: Findings from the National Institute of Child Health and Human Development Study. Retrieved from ProQuest Digital Dissertations.

Weinstein, N.D. (1993). Testing four competing theories of health protective behaviour. Health Psychology, 12, 324-333.

World Health Organization (WHO). (2010). WHO Global Infobase data for saving lives. Estimated overweight \& obesity $(B M I \geq 25 \mathrm{~kg} / \mathrm{m} 2)$ prevalence. Trends data [Data file]. Retrieved from https://apps.who.int/infobase/ Comparisons.aspx

World Health Organization (WHO). (2011). Obesity and overweight. Retrieved August 15, 2011, from http://www.who.int/ mediacentre/factsheets/fs311/en/

World Health Organization (WHO). (2012). Global health observatory. Mean body mass index. Retrieved May 1, 2012, from http://www.who.int/gho/ncd/risk_factors/bmi_text/en/ index.html 